Supporting Information

\title{
Cationic Covalent Organic Framework as an Ion Exchange Material for Efficient Adsorptive Separation of Biomolecules
}

Imann Mosleh ${ }^{1,2}$, Ahmad R. Khosropour $^{2}$, Hazim Aljewari ${ }^{1}$, Christina Carbrello ${ }^{3}$, Xianghong

Qian $^{4}$, Ranil Wickramasinghe ${ }^{1}$, Alireza Abbaspourrad ${ }^{2}$, Robert Beitle ${ }^{1 *}$.

*E-mail: rbeitle@uark.edu

${ }^{1}$ Ralph E. Martin Department of Chemical Engineering, University of Arkansas, Fayetteville, AR 72701, USA. ${ }^{2}$ Department of Food Science, Cornell University, Ithaca, NY 14850, USA. ${ }^{3}$

MilliporeSigma Corporation, Bedford, Massachusetts, 01730, USA. ${ }^{4}$ Department of Biomedical Engineering, University of Arkansas, Fayetteville, AR 72701, USA 
Table of Contents

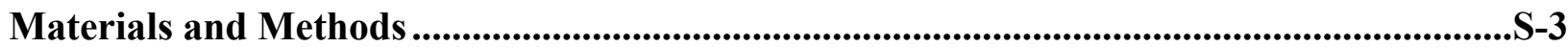

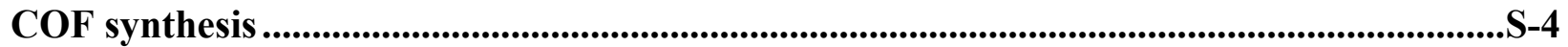

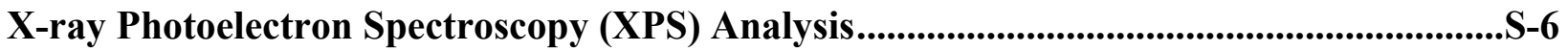

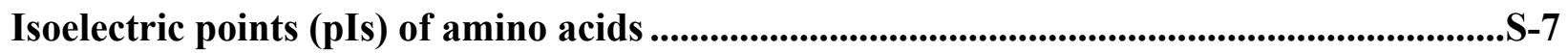

Adsorption capacity evaluation .........................................................................................9

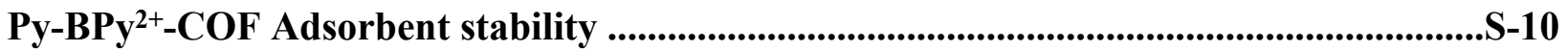

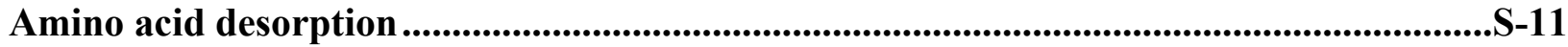

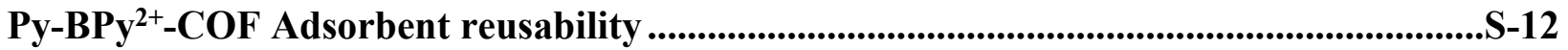

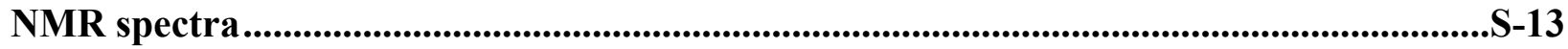

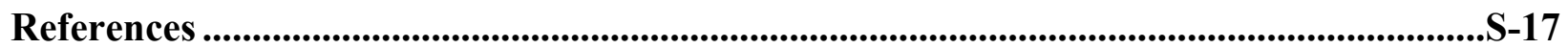




\section{Materials and Methods}

N,N'-Dimethylformamide (DMF), dichloromethane $\left(\mathrm{CH}_{2} \mathrm{Cl}_{2}\right)$, tetrahydrofuran (THF), chloroform $\left(\mathrm{CHCl}_{3}\right)$, methyl alcohol $(\mathrm{MeOH})$, acetonitrile, acetone, ether, and acetic acid were purchased from Macron Fine Chemicals TM, Avantor Performance Materials (Center Valley, PA). Anhydrous dioxane and sodium periodate were purchased from TCI America (Portland, OR), Alfa Aesar (Ward Hill, MA), and Sigma (St Louis, MO), respectively. 4-(4,4,5,4tetramethyl-1,3,2-dioxabordan-2-yl)aniline, palladium tetrakis(triphenyl phosphine), dibromoethane, nitrobenzene, and 1,3,6,8-tetrabromopyrene were purchased from TCI America (Portland, OR). 5,5'-Dimethyl-2,2'-bipyridine, $t$-butoxybis (dimethylamino)methane, sodium dithionite, cytochrome $\mathrm{C}$, bovine serum albomin (BSA), lysozyme, alanine, aspartic acid, glutamic acid, histidine, leucine, and tryptophan were purchased from Sigma (St Louis, MO).

NMR spectra $\left({ }^{1} \mathrm{H}\right.$ and $\left.{ }^{13} \mathrm{C}\right)$ were recorded using $400 \mathrm{MHz}$ NMR spectrometer at room temperature in DMSO- $d 6$ solution. Chemical shifts $\delta$ are reported in ppm, and the abbreviations $\mathrm{s}, \mathrm{d}, \mathrm{t}, \mathrm{q}, \mathrm{m}$, and $\mathrm{J}$ are used for singlet, doublet, triplet, quartet, multiplet, and coupling constant, respectively.

HPLC solvent A was $0.1 \%$ Trifluoroacetic Acid (TFA) in water while solvent B was $0.09 \%$ TFA in a mixture of $80 \%$ acetonitrile and $20 \%$ water. 


\section{COF synthesis}

A method adapted from Mi et al. was followed for cationic covalent organic framework (Py$\left.\mathrm{BPy}^{2+}-\mathrm{COF}\right)$ synthesis [1].

\section{[2,2'-bipyridine]-5,5'-dicarbaldehyde (2,2'-BPy-DCA) synthesis}
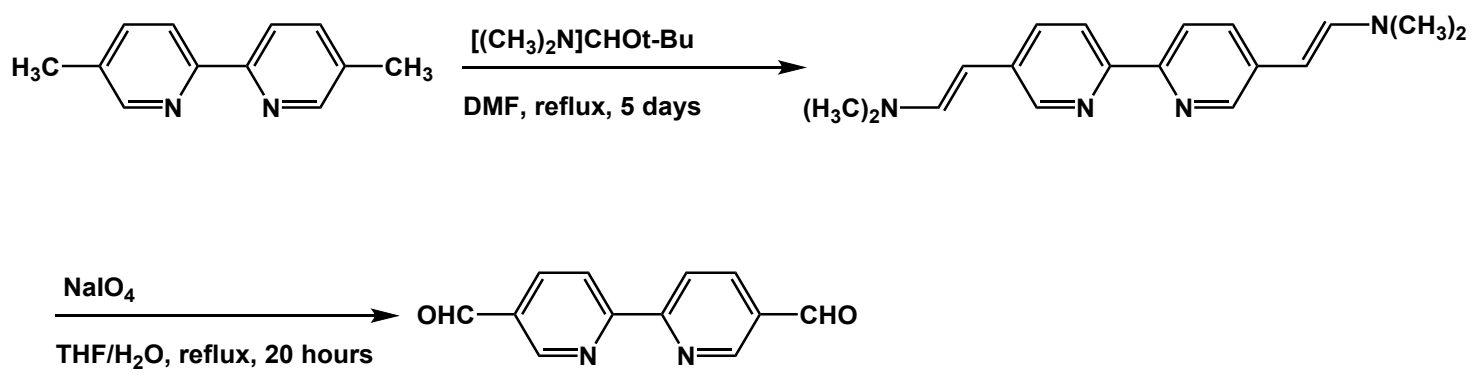

Briefly, 2,2'-BPy-DCA was synthesized by mixing of 5,5'-dimethyl-2,2'-bipyridine (100 $\mathrm{mg}, 0.54 \mathrm{mmol})$, and $t$-butoxybis(dimethylamino)methane $(1 \mathrm{~mL})$ in DMF $(1 \mathrm{~mL})$ inside a Pyrex tube. After five cycles of freeze pump thaw treatment, the reaction was proceeded at $120^{\circ} \mathrm{C}$ for 5 days. 5,5'-bis(2-dimethylaminovinyl)- 2,2'-bipyridine was synthesized in a form of yellow powder after filtration, diethyl ether triple wash, and drying under vacuum overnight at $60{ }^{\circ} \mathrm{C}$ (yield 47\%). $100 \mathrm{mg}(0.34 \mathrm{mmol})$ of 5,5'-bis(2-dimethylaminovinyl)- 2,2'-bipyridine was then mixed in $\mathrm{CH}_{2} \mathrm{Cl}_{2}(4.5 \mathrm{~mL})$ and THF $(15 \mathrm{~mL})$. Subsequently, the prepared mixture was added to 3 $\mathrm{mL}$ of aqueous solution of sodium periodate $(0.553 \mathrm{~g}, 2.6 \mathrm{mmol})$ and stirred for 20 hours at room temperature. After concentration and extraction with $\mathrm{CHCl}_{3}$, the solid phase was filtered out. The solid phase was dried over $\mathrm{MgSO}_{4}$ and washed with $\mathrm{MeOH}$ and 2,2'-BPy-DCA was obtained in a form of white powder in $69 \%$ yield.

${ }^{1}$ H NMR (400 MHz, DMSO-d6) $\delta 10.21$ (s, 2H), 9.24 (s, 2H), 8.69 (d, J = 8.6 Hz, 2H), 8.47 (dd, $\mathrm{J}=8.3,2.0 \mathrm{~Hz}, 2 \mathrm{H})$.

${ }^{13}$ C NMR (101 MHz, DMSO-d6) $\delta 192.57,158.51,152.01,138.05,132.16,122.39$. 


\section{4,4',4",4"'-(Pyrene-1,3,6,8-tetrayl) tetraaniline (Py-TA) synthesis}

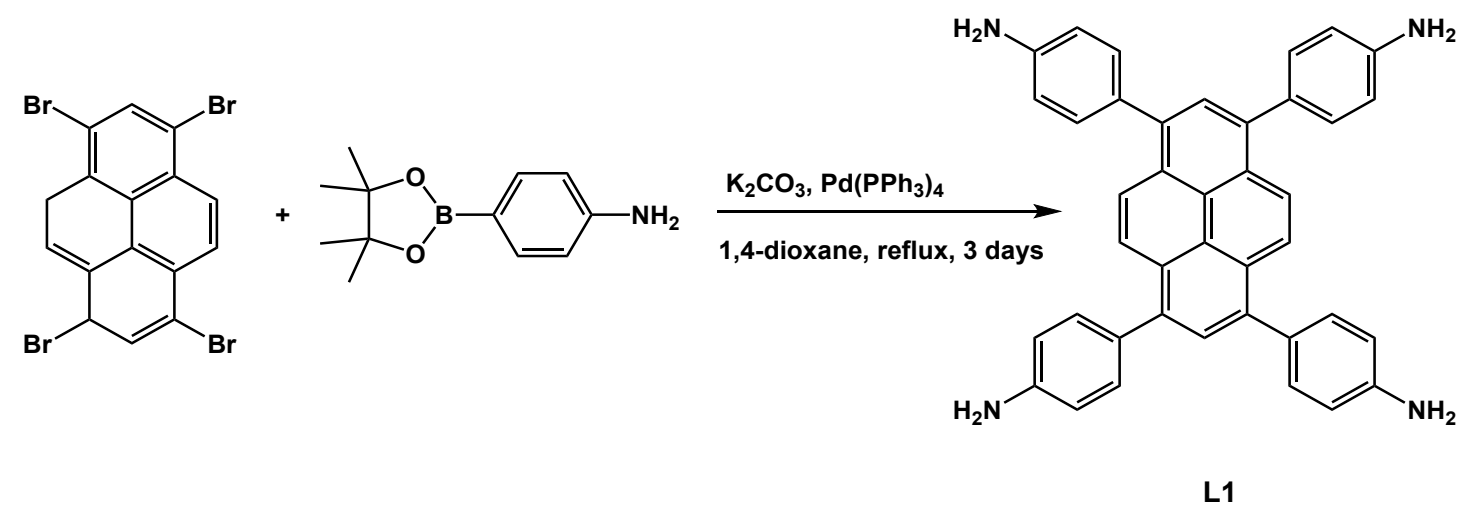

To synthesize 4,4',4",4'"-(Pyrene-1,3,6,8-tetrayl) tetraaniline (Py-TA) as COF linker, SuzukiMiyaura coupling reaction was exploited. The reaction was performed between 1,3,6,8Tetrabromopyrene (500 mg, $0.96 \mathrm{mmol})$ and 4-(4,4,5,5-tetramethyl- 1,3,2-dioxaborolan-2yl)aniline $(1.27 \mathrm{~g}, 5.8 \mathrm{mmol})$ in the presence of palladium tetrakis(triphenyl phosphine) (0.06 $\mathrm{g}$, $0.05 \mathrm{mmol})$ as catalyst and potassium carbonate $(1.05 \mathrm{~g}, 7.6 \mathrm{mmol})$ as base in dioxane $(15 \mathrm{~mL})$. The mixture was refluxed under argon for 3 days, added to $10 \mathrm{~mL}$ dioxane anhydrous, and were treated with $10 \mathrm{~mL}$ of DI water. After filtration, the precipitate was separated from the mixture and Py-TA in the form of light-yellow powder was obtained without further purification (yield $90 \%)$.

${ }^{1}$ H NMR (400 MHz, DMSO-d6) $\delta 8.14(\mathrm{~s}, 4 \mathrm{H}), 7.80(\mathrm{~s}, 2 \mathrm{H}), 7.36(\mathrm{~d}, J=8.4 \mathrm{~Hz}, 8 \mathrm{H}), 6.78(\mathrm{~d}, J$ $=8.4 \mathrm{~Hz}, 8 \mathrm{H}), 5.31(\mathrm{~s}, 8 \mathrm{H})$.

${ }^{13}$ C NMR (101 MHz, DMSO-d6) $\delta$ 148.68, 137.60, 131.52, 129.50, 128.08, 127.20, 126.60, $124.90,114.42$. 


\section{X-ray Photoelectron Spectroscopy (XPS) Analysis}
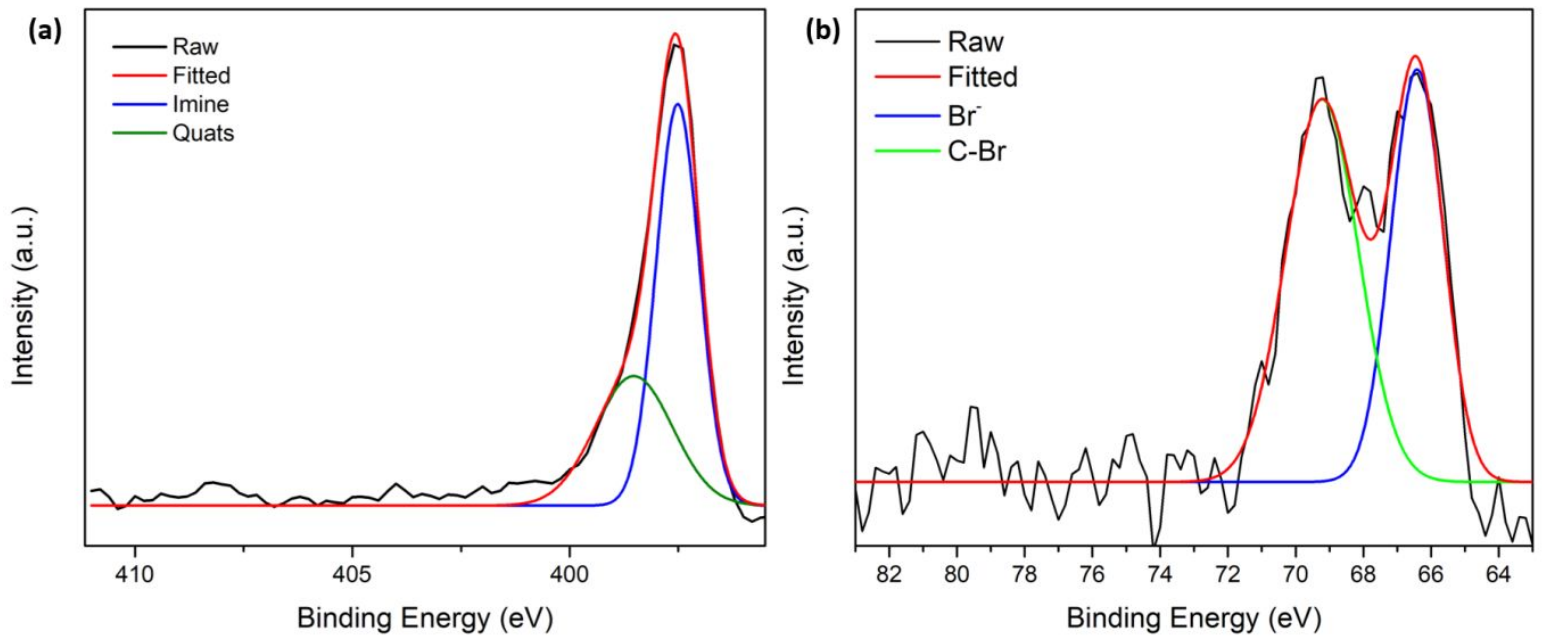

Figure S1. XPS spectra of (a) N 1s and (b) Br 3d.

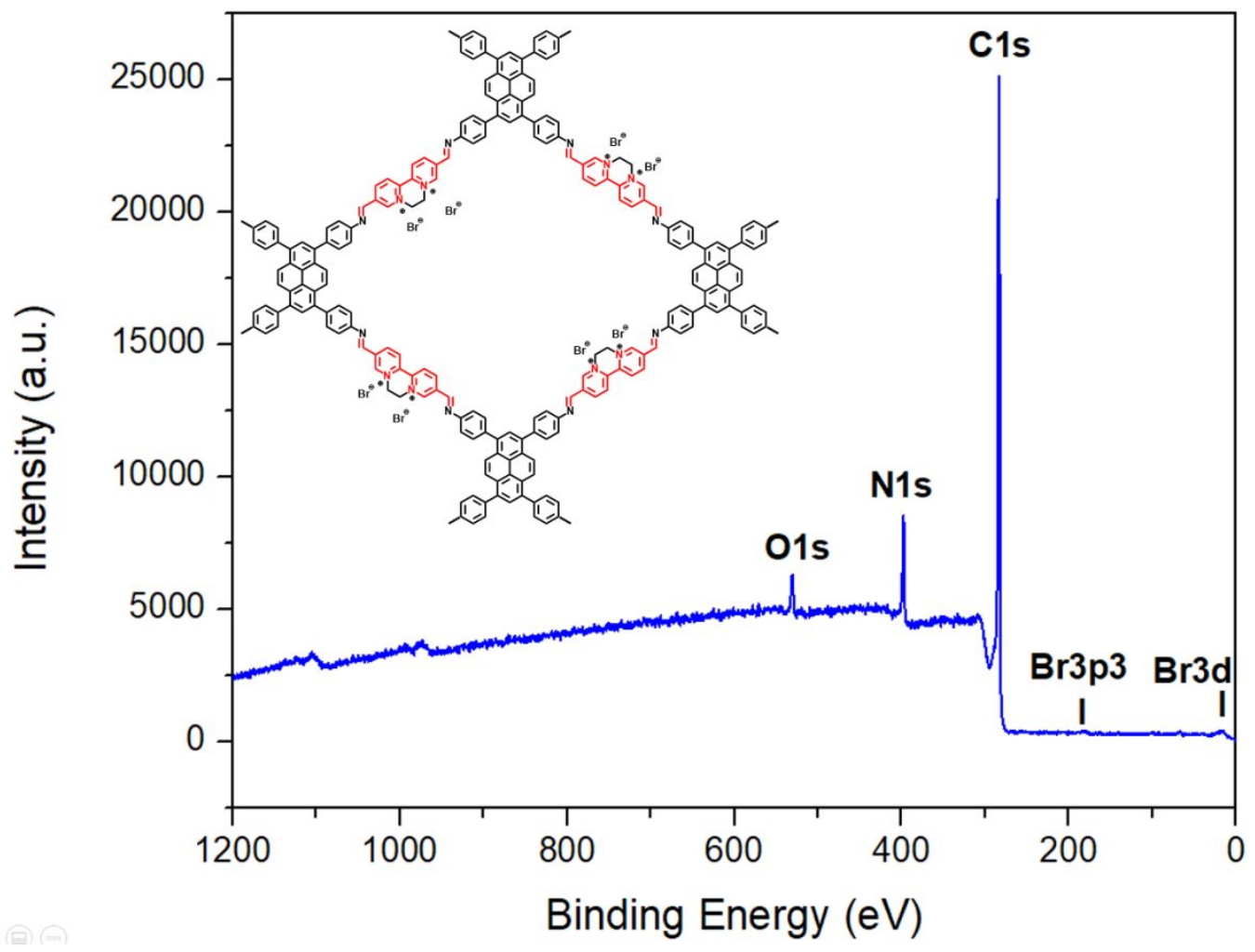

Figure S2. XPS survey spectrum of $\mathrm{Py}-\mathrm{BPy}^{2+}-\mathrm{COF}$. 
Isoelectric points (pIs) of amino acids

Table S1. Amino acids and their isoelectric points (pIs) at room temperature.

\begin{tabular}{|c|c|c|c|c|c|c|}
\hline Amino acid & Alanine & Aspartic Acid & $\begin{array}{c}\text { Glutamic } \\
\text { Acid }\end{array}$ & Histidine & Leucine & Tryptophan \\
\hline pI value & 6.11 & 2.98 & 3.08 & 7.64 & 6.04 & 5.88 \\
\hline
\end{tabular}




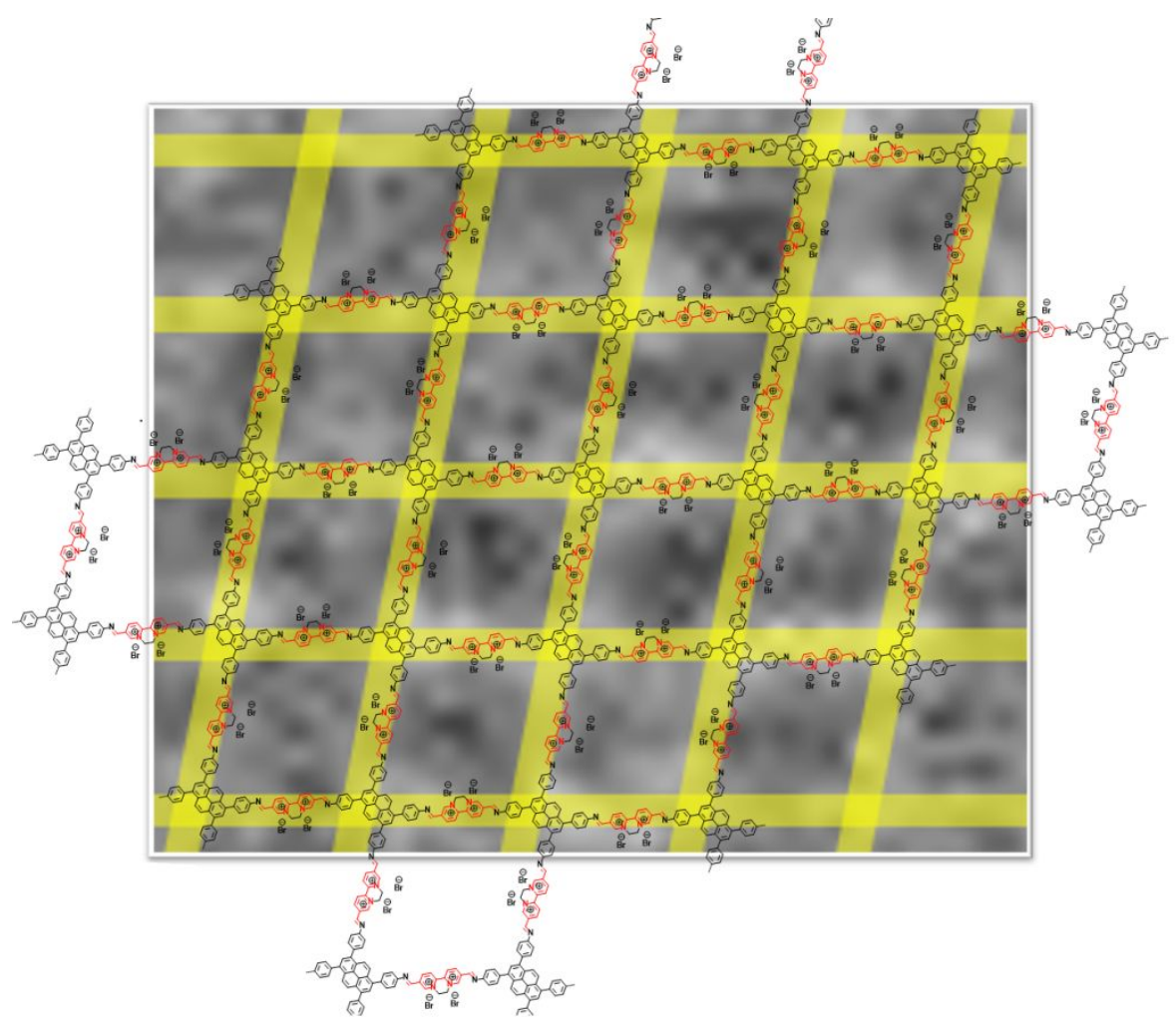

Figure S3. HRTEM image of Py-BPy ${ }^{2+}-\mathrm{COF}$. The TEM image matches with the COF structure. 
Adsorption capacity evaluation

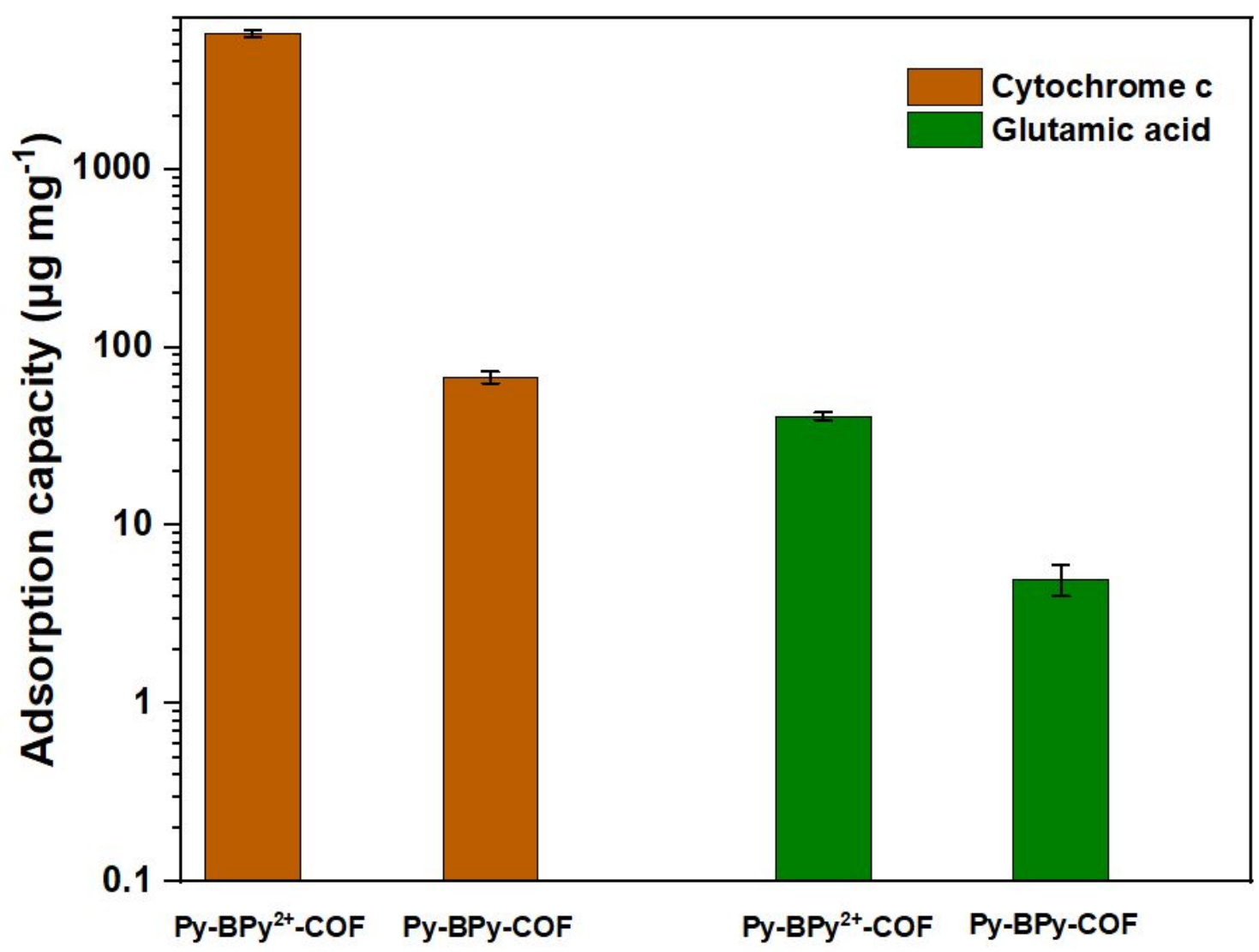

Figure S4. Adsorption capacity evaluation of Py-BPy-COF and $\mathrm{Py}-\mathrm{BPy}^{2+}-\mathrm{COF}$ using cytochrome $\mathrm{c}$ and glutamic acid. 
Py-BPy ${ }^{2+}-$ COF Adsorbent stability

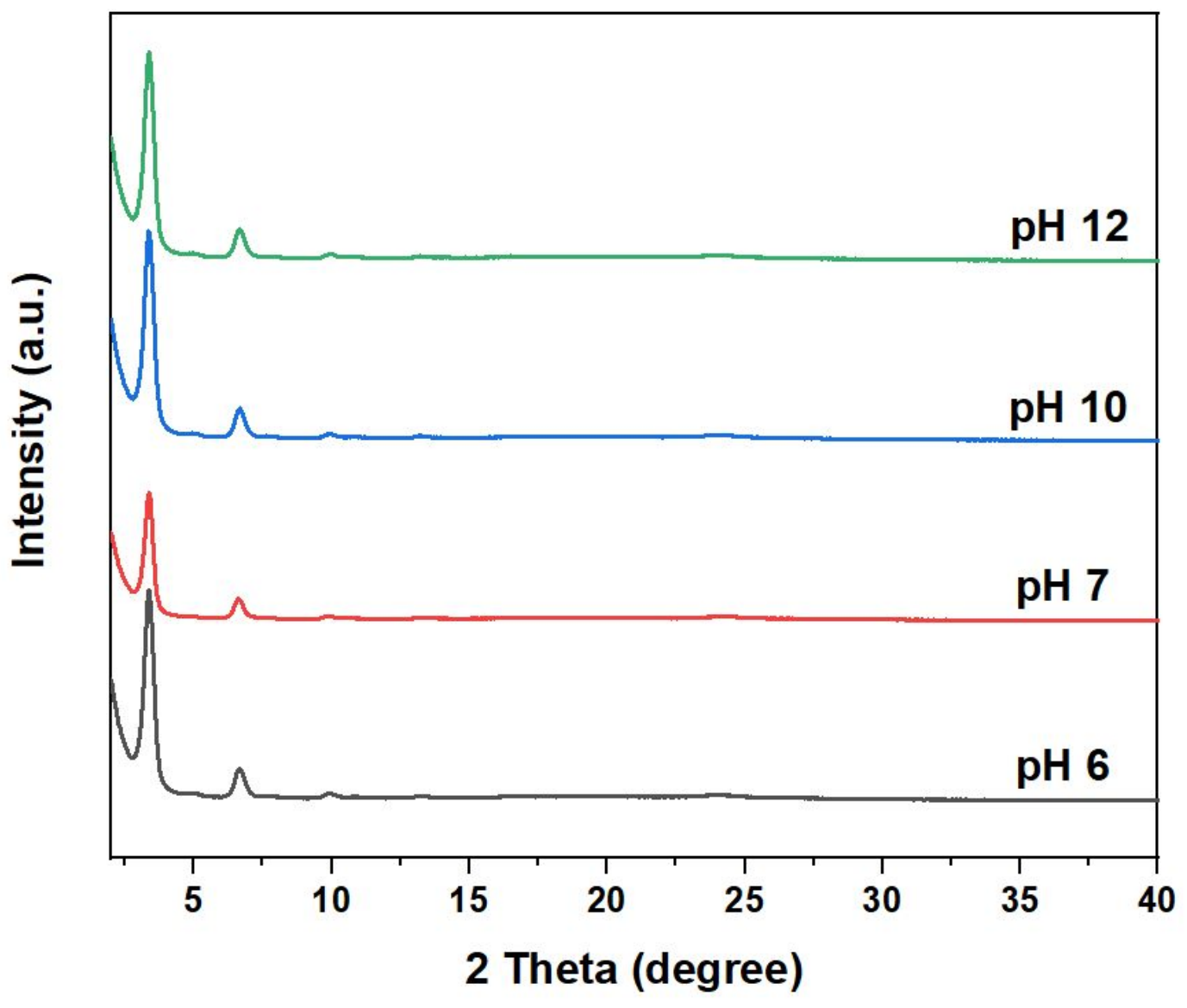

Figure S5. $\mathrm{Py}-\mathrm{BPy}^{2+}-\mathrm{COF}$ stability study at different $\mathrm{pH}$ values. 
Amino acid desorption

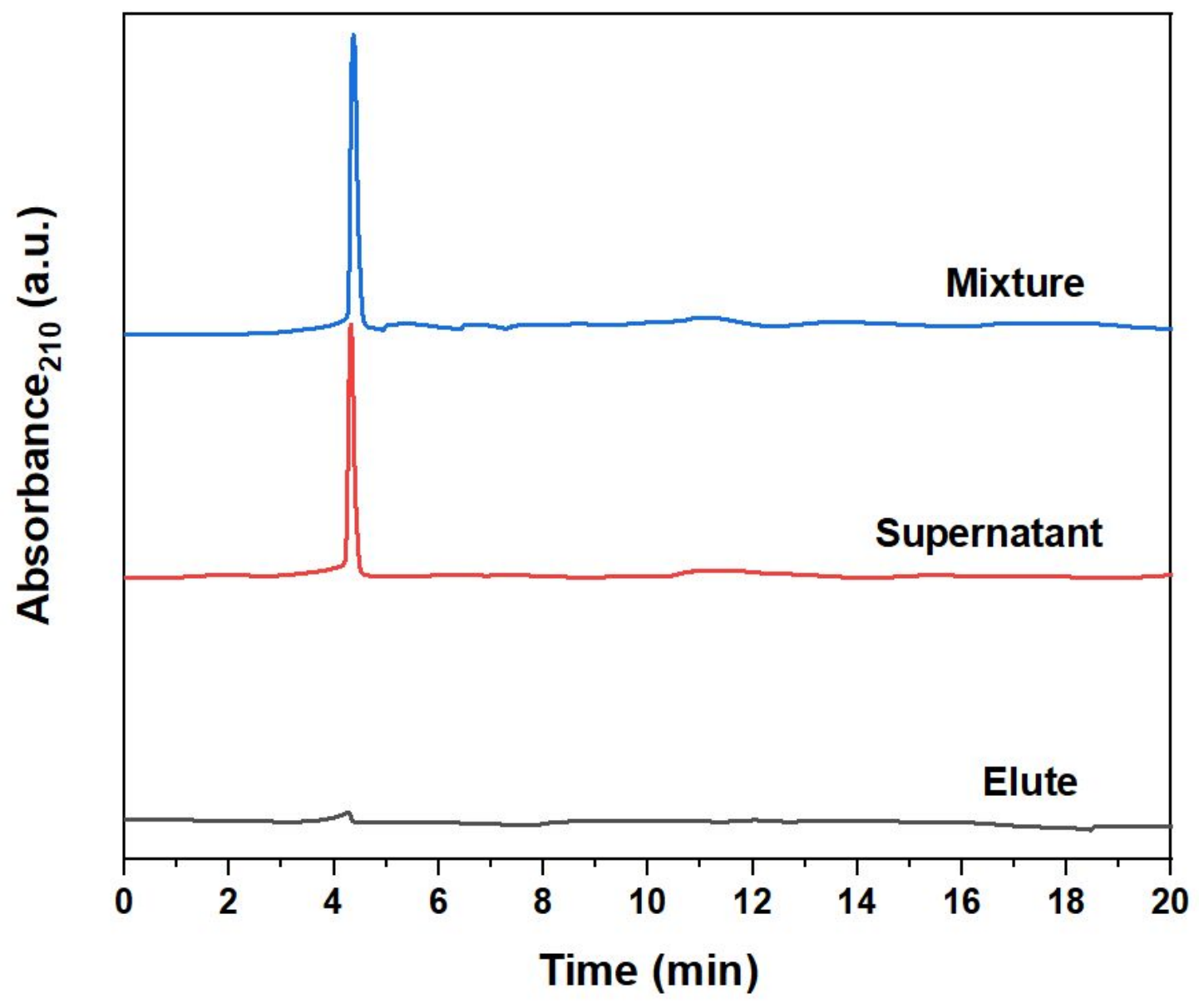

Figure S6. Amino acid desorption evaluation of $\mathrm{Py}-\mathrm{BPy}{ }^{2+}-\mathrm{COF}$ using glutamic acid. 
Py-BPy ${ }^{2+}-$ COF Adsorbent reusability

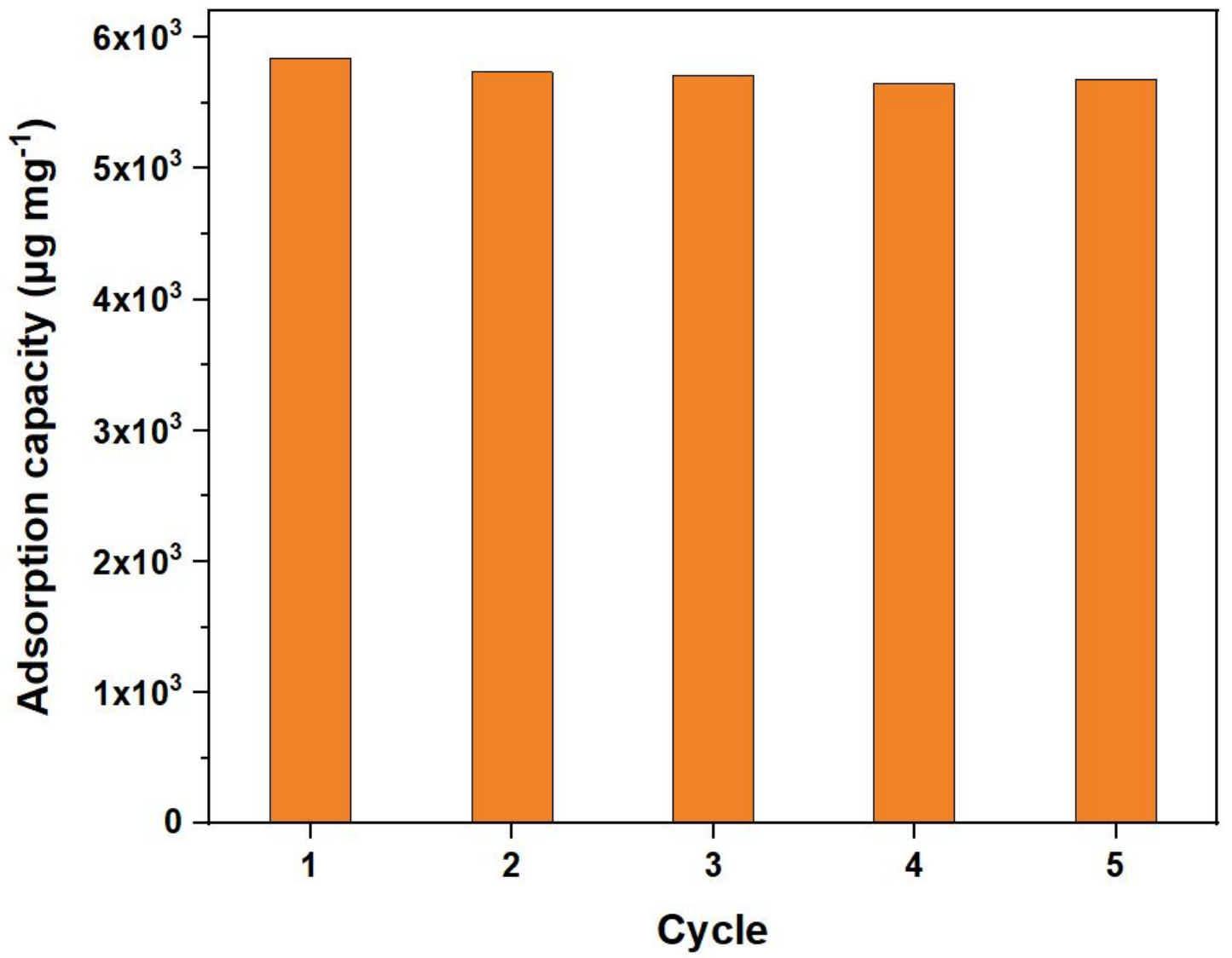

Figure S7. Reusability evaluation of the regenerated $\mathrm{Py}-\mathrm{BPy}^{2+}-\mathrm{COF}$ adsorbent using cytochrome c protein. 
NMR spectra
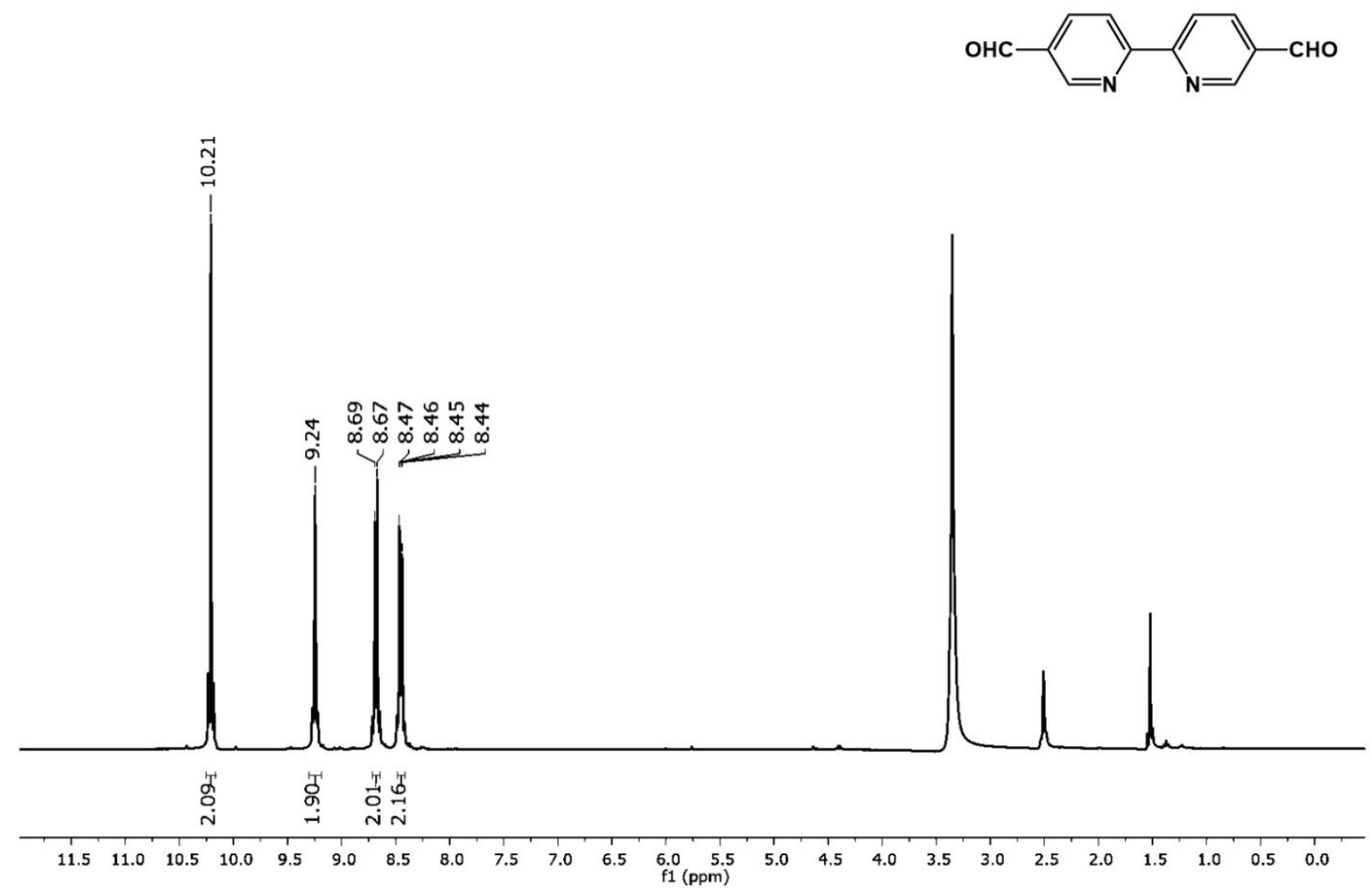

Figure S8. ${ }^{1} \mathrm{H}$ NMR (400 MHz, DMSO- $\left.d_{6}\right)$ spectrum. 


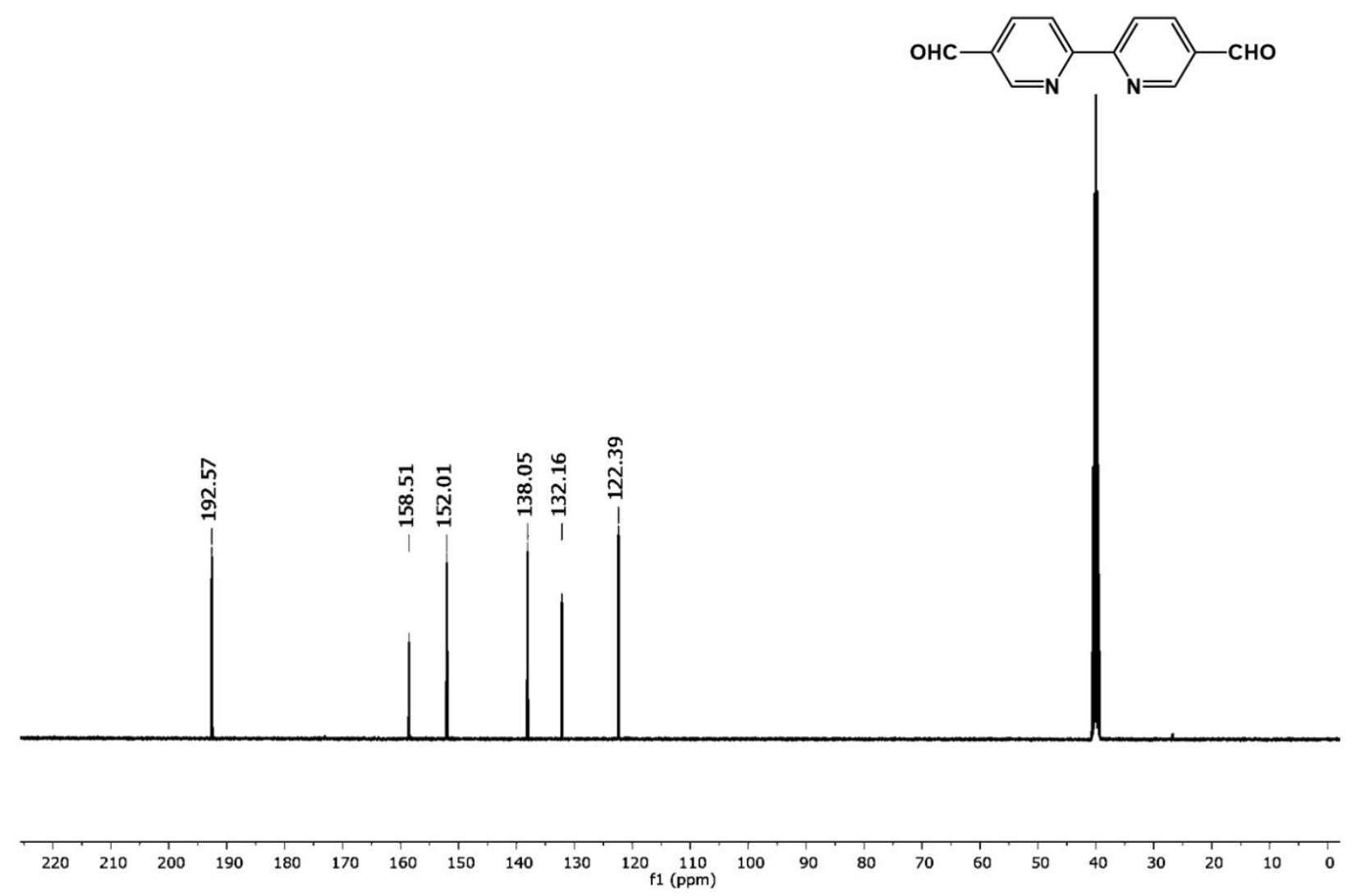

Figure S9. ${ }^{13} \mathrm{C}\left\{{ }^{1} \mathrm{H}\right\}$ NMR (400 MHz, DMSO- $\left.d_{6}\right)$ spectrum. 


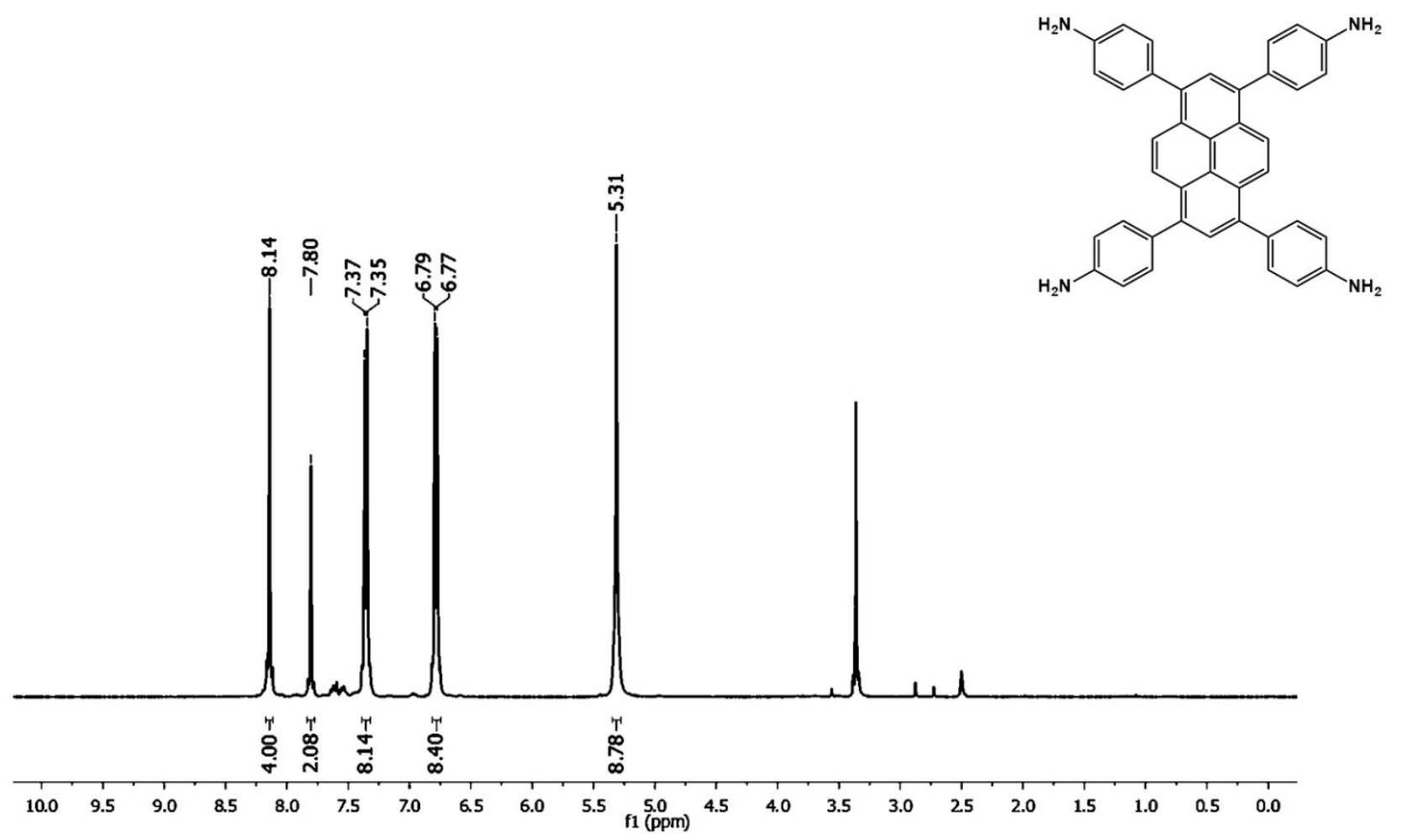

Figure S10. ${ }^{1} \mathrm{H}$ NMR $\left(400 \mathrm{MHz}, \mathrm{DMSO}-d_{6}\right)$ spectrum. 


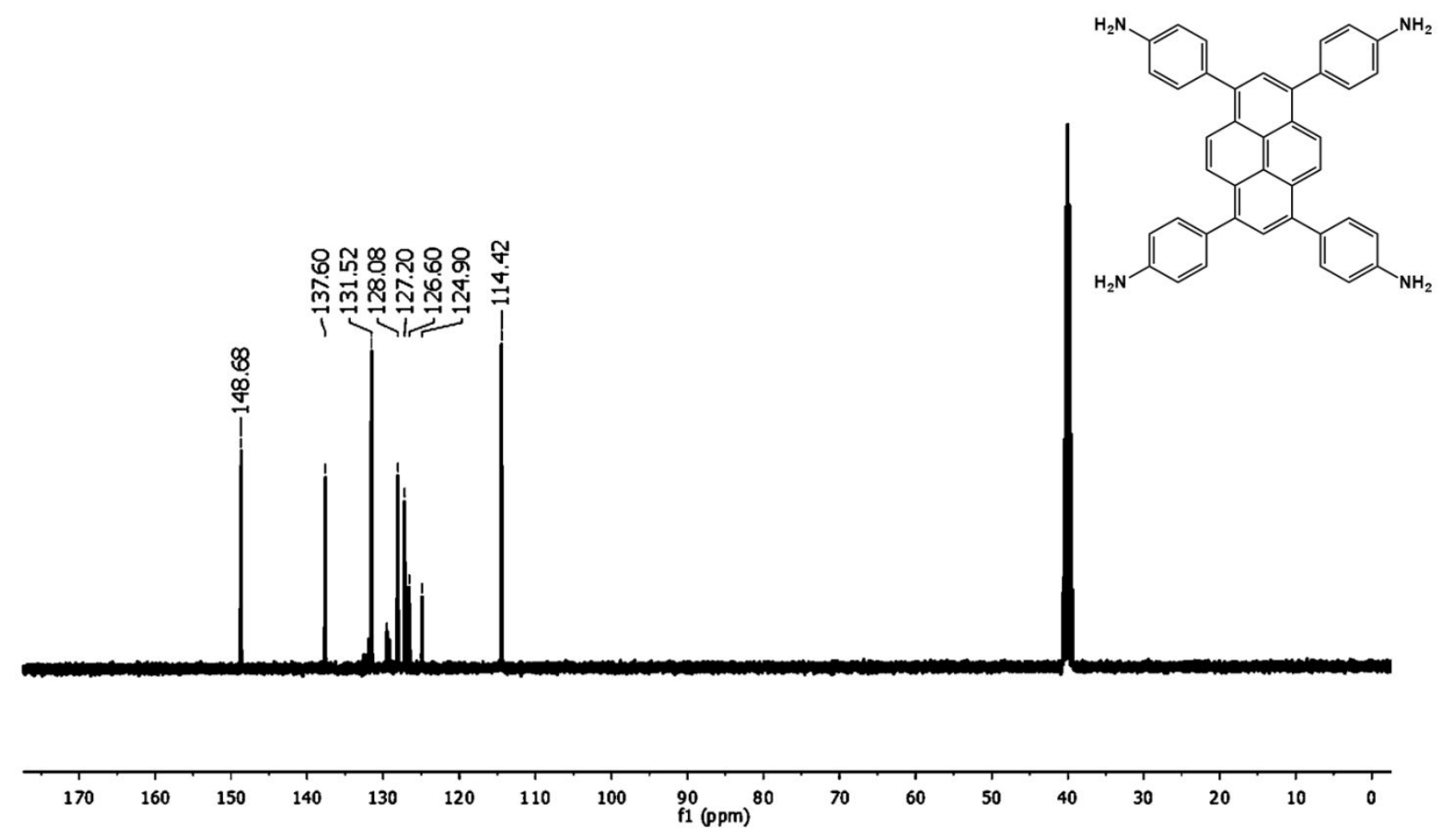

Figure S11. ${ }^{13} \mathrm{C}\left\{{ }^{1} \mathrm{H}\right\}$ NMR (400 MHz, DMSO- $\left.d_{6}\right)$ spectrum. 


\section{References}

(1) Mi, Z.; Yang, P.; Wang, R.; Unruangsri, J.; Yang, W.; Wang, C.; Guo, J. Stable Radical Cation-Containing Covalent Organic Frameworks Exhibiting Remarkable Structure-Enhanced Photothermal Conversion. J. Am. Chem. Soc. 2019, 141 (36), 14433-14442.

https://doi.org/10.1021/jacs.9b07695. 